SHS Web of Conferences 24, 02010 (2016)

DOI: $10.1051 /$ shsconf/20162402010

(C) Owned by the authors, published by EDP Sciences, 2016

\title{
Teaching of Chinese grammars for Hungarian students and study of teaching-grammars
}

\author{
Min Zhu \\ College of Humanities, Hubei University of Science and Technology, Xianning, Hubei, China
}

\begin{abstract}
The author taught foreign students Chinese in the Confucius Institute of EötvösLoránd University in Hungary for two years. The mother tongue of Hungarian students is Hungarian in most cases. As Hungarian language (hereinafter referred to as "Hungarian") is a typical agglutinative language while Chinese is a typical isolating language, there are immeasurably vast differences between the grammatical systems of these two languages. This paper conducted discussion on the problems in teaching Hungarian students Chinese grammars mainly based on three aspects: 1 . the similarities and differences between study of Chinese grammars and teaching of Chinese grammars for foreign students; 2. brief summary of the grammatical differences between Chinese and Hungarian to understand several grammatical mistakes which Hungarian students always make; 3. some strategies of teaching Hungarian students Chinese grammars.
\end{abstract}

Keywords: Hungarian; teaching grammar; teaching Chinese as a foreign language; grammar teaching

\section{INTRODUCTION}

While teaching Hungarian students Chinese, I could always hear students saying:

$(1)^{*}$ wo xuexi zai xuexiao. (I study Chinese in school.)

(2)*wo mama gongzuo meitian xiawu. (My mom works every day in the afternoon.)

(3)*ta you yi shu. (She has one book.)

(4)*ta shi zhiyuan de gongsi. (He is staff's company.)

To solve these problems, common sense of Chinese grammars must be referred to. It is unfortunate that many TCSL (Teaching Chinese as a Second Language) teachers are radical in Chinese grammar teaching - some teachers completely abandon grammatical knowledge and correct the syntax error made by students one by one while some teachers pay too much attention to grammars. In the former situation, students may remember the correct syntax of this sentence, but they may make the same mistake in another sentence of the same type. In the latter situation, no class can be given without grammar and students may get confused as a result.

Therefore, this paper conducted discussion on the problems in teaching Hungarian students Chinese grammars mainly based on three aspects: 1 . the similarities and differences between study of Chinese grammars and teaching of Chinese grammars for foreign students; 2 . brief summary of the grammatical differences between Chinese and Hungarian to understand several grammatical mistakes which Hungarian students always make; 3 . some strategies of teaching Hungarian students Chinese grammars.

\section{RELEVANCE AND DIFFERENCE BETWEEN CHINESE GRAMMARS AND GRAMMARS OF TEACHING CHINESE AS A FOREIGN LANGUAGE}

For the question of whether to teach grammar in the teaching of Chinese as a second language, countless predecessors have given positive answers. This is decided by the principle of second language acquisition. In the teaching of Chinese as a second language, the teaching objects are students who already have their mother tongue as the first language. If the students are only told to stimulate and receive no teaching of grammar, they will only get half the achievement with twice the effort and lose interest in learning Chinese.

First of all, let's take a look at the relations between Chinese grammar and grammar in the teaching of Chinese as a second language. 


\section{SHS Web of Conferences}

Study of Chinese grammar lays the foundation in the teaching of Chinese as a second language. People who know little grammar have no idea of how to start teaching Chinese. Just as what De-Xi Zhu (1989) said, "The teaching of Chinese as a second language must rely on Chinese study; or it will be like a tree without origin or roots." "The reason why there're many questions cannot be clearly explained in the class is because fundamental research is in shortage." "It shall be emphasized that Chinese study is the foundation of teaching Chinese as a second language. It is a reserve force. Without Chinese study, the teaching of Chinese as a second language cannot make any progress." Quan Li (2003) once directly pointed out that "It is not decided by our will or responsibility of whether to conduct grammatical study. Grammatical study is a must...in the long run; grammatical study is the fundamental way to improve the level and efficiency of the teaching of Chinese as a second language."

Is it true that grammar used in the teaching of Chinese as a seconding language is the same with Chinese grammar? Of course not! We always say that experts of Chinese grammar may not be able to give a good lesson on Chinese for foreigner due to three main reasons: 1. Although study of Chinese grammar has made great progress in recent years, the achievement that can be referred to in the teaching of Chinese as a second language is far away from being sufficient. This reason can also interpret why there are many linguistic phenomena we can't explain. 2. The study directions and study objects about the study of Chinese grammar and grammar used in the teaching of Chinese as a second language are totally different. The former ones mainly include method of induction which is to conclude and analyze existing linguistic data and find some rules and laws; the latter ones mainly include deductive method which is to directly teach students the rules and how to use the rules. 3 . Grammar study is mainly about long-drawn and tedious documents which are hard to understand and impropriate to be used in teaching directly. Teaching grammar requires teachers to concisely summarize the rules for students to master.

Therefore, we cannot simply use "borrowism" and talk volubly of Chinese grammar in class of teaching Chinese for foreigners. Not to mention grammatical knowledge is dull and boring that goes against the principle of "edutainment" in the teaching of Chinese as a second language, the saying of "all grammatical rules have exceptions" alone can bring teachers headache. Moreover, study of Chinese grammar is the ontology research of language. It is pure theory. However, teaching grammar is actually practical study These two kinds of grammar are not the same research object and even don't share the same research interest. It is natural that there is no equal mark between Chinese grammar and teaching grammar.

Till now, we should be clear that we must teach grammar in the class of teaching Chinese for foreign- ers. However, the grammar here refers to "teaching grammar" which is based on the ontology research of Chinese grammar. This grammar is used for teaching service and thus must be concise, practical and highly generalized. It is better not to use too many terminologies in teaching grammar, and thus can help students master the usage rules of Chinese grammar unconsciously.

\section{EXAMPLE ANALYSIS OF STRAIGHT COMPARISON OF THE DIFFERENCES BETWEEN CHINESE AND HUNGARIAN GRAMMARS}

We have understood what Chinese teaching grammar is now. Then, how to establish teaching grammar with higher pertinence? Our primary task is to study the grammatical differences between the interlanguage of research object and Chinese grammar. TCSL (Teaching Chinese as a Second Language) teachers can only predict student's bias error caused by "negative transfer" better after understanding the similarities and differences between these two. In the meantime, it is easier for teachers to master the difficulty of teaching grammar-which grammar rules are difficult for students and which are easy.

The reason for why I use "interlanguage" instead of "mother tongue" is because teacher's teaching language may not be student's mother tongue in certain situations. For example, in Hungary, our TCSL teachers use English in the class in most cases. Therefore, in this kind of class, negative transfer is not only reflected on student's mother tongue, but also on English. However, most Hungarian students speak Hungarian as their mother tongue, TCSL teachers do not have to spend a long time in studying Hungarian. A little understanding of the grammatical differences between Chinese and Hungarian is very necessary.

Chinese belongs to Sino-Tibetan languages while Hungarian belongs to Finland-Ugric branch. Chinese is typical isolating language while Hungarian is typical agglutinative language. There are distinct differences in the hierarchical classifications and grammatical features of these two languages. Hence, Hungarian is the most difficult language for most Chinese to learn. For Hungarians, if they want to describe something is very difficult, they would use Chinese in comparison.

However, it is very hard for me to compare the differences between Chinese and Hungarian. On one hand, I've just learned quite a little Hungarian, barely with any study of it. In order to teach Hungarian students Chinese, I have to understand the differences between Chinese and Hungarian. On the other hand, I've just come to Hungary to teach Chinese for some time and all my students start learning Chinese from zero. As a result, all the grammatical comparisons shown below are basically the problems that junior 
students have.

I tried to list and briefly summarize the direct and distinct differences between Chinese and Hungarian according to my knowledge in this paper as follows:

1. Morphologic change. Morphologic change can be regarded as the most distinct difference between Chinese and Hungarian. As Hungarian is agglutinative language, it grammatical category is usually expressed by adding suffixes. Therefore, the morphologic changes of Hungarian are various. Chinese is isolating language and its morphologic changes are much less than those of Hungarian. Hungarian students think this difference makes Chinese easy to learn. Meanwhile, as there's no change of word class, number and format in Chinese, the flexible syntactic combinations in Chinese always make Hungarian students lose their mind. For example, in Hungarian, if a subject is a personal pronoun, it wouldn't appear in most cases as its verbal inflection can express the order of grammatical person. However, there is no change of format in Chinese. When a student makes a sentence, he has to make sure what the subject is at first. Moreover, there're single and plural forms in Chinese. While expressing plurals, Hungarian students would unconsciously use "men" (which is the same as the meaning of "s" in English) such as "Ta men shi wo de xue sheng men" (They are my students).

2. Word order. As everyone knows, word order and function word are the two major features of Chinese because there are very few morphologic changes in Chinese. Word order is no important in Hungarian in most cases. The sentence patterns of "S+V+O" and "S $+\mathrm{O}+\mathrm{V}$ " are both applicable. Hence, Hungarian students think it is very hard to remember fixed word order, especially the position of adverbial modifier. Due to the influence of dual-negative transfer from Hungarian and English, they always put adverbial modifier at the end of a sentence such as examples (1) and (2) listed above and sentences like "Ta kai che ye" ("She drives, too" in English. The right order in Chinese shall be "Ta ye kai che").

3. Classifier. Hungarian students and other foreign students find it difficult to clarify the abundant classifiers in Chinese. These students cannot use classifiers properly. Sometimes they do not use classifiers at all due to the influence of negative transfer such as example (3). Some students know they should use classifiers but misuse them such as "Ta jia you san koumao" "She has three cats at home" in English. It shall be "Ta jia you san zhimao" in Chinese).

4. Complement. As there is no complement in Hungarian, most students do not know how to understand what it is. However, Chinese contains rich complement components. Of course, this problem mainly occurs in middle and senior Chinese teaching. Analysis will be given below.

\section{SOME STRATEGIES FOR TEACHING HUNGARIAN STUDENTS CHINESE GRAMMARS}

Since it has been defined that teaching grammar must be used in class of teaching Chinese as a second language, what are the relations between teaching grammar and grammar teaching?

Teaching grammar emphasizes on grammar of which the central point is the grammatical knowledge serving for teaching. Thus, teaching grammar is theoretical. However, grammar teaching belongs to teaching method. It is a teaching strategy studied for better grammar teaching.

Based on the brief comparison between Chinese grammar and Hungarian grammar and the Chinese teaching experience I have obtained from my Hungarian students, I'll propose some effective grammar teaching strategies which I think can be helpful in teaching Hungarian students Chinese.

1. Morphologic change. Tell students who start from zero that there's no change of word character, number or format in Chinese. In their sub- consciousness, they will think Chinese is not as hard as they think. Reduction of fear of difficulty is good for keeping the interest in learning Chinese.

2. Problem of Chinese word order. There's no high requirement set for word order in Chinese. Therefore, Hungarian students always collect a pile of words without order while speaking Chinese. In Chinese, it is not allowed to do so. Sometimes, a wrong position of a word can make the whole sentence wrong. This problem must be repeated again and again, in order to make students realize how important word order is.

First of all, let's talk about subject-verb-object order. In Chinese, the right sentence pattern is " $\mathrm{S}+\mathrm{V}+\mathrm{O}$ ". Although the sentence pattern is " $\mathrm{S}+\mathrm{O}+\mathrm{V}$ " in Hungarian, it is not hard for the students to understand " $\mathrm{S}+\mathrm{V}+\mathrm{O}$ " because we basically teach in English and they have English foundation. There's no need to repeat or emphasize this part. Sometimes, excessive explanation can make students confused. After practicing some simple common expressions such as "Wo shi xue sheng" ("I'm a student"), students can basically master the expressions. Interrogative pronouns are always put at the beginning of sentences in English and Hungarian grammatical rules. Therefore, students always make mistakes in word order and we have to remind them.

Besides, positions of adverbial modifiers and attributives are the difficult part in Chinese and English, such as sentence 1 and sentence 2 listed above. Emphasize that "Adverbial modifiers must be put before the modified verbs in Chinese" to students since they start learning Chinese. This method can make it easy for students to understand and accept. Of course, this rule has to be repeated again and again. After all, the effect of negative transfer is great, while students may unconsciously speak out sentences like sentence 1 and 
sentence 2. There is a wide range of adverbial modifiers such as "I also am student", "I at Szeged work", "I every Monday go to the library" and "She from France comes". Naturally, students can develop a thinking habit of paying attention to the positions of adverbs in their early stage of Chinese learning. Problem about the positions of attributives can get in on the act. But we have to avoid using too many terminologies while giving explanation.

3. Classifier. This problem looks difficult but is very simple indeed. Sometimes students think something is hard because it is new. However, as it is new, the influence that interlanguage negative transfer leaves on students will be the least, making it much easier for students to understand. Tell the students that there are classifiers in Chinese, they will understand. The rest of the study relies on students themselves. They have to spend certain time and master the use of nouns with classifiers and verbs with classifiers. In the long term of study, students can accumulate more and more classifiers step by step. In addition, during my teaching experience, when I told my students "The combination of a noun and a classifier shall be used between a numeral and a name in Chinese, and there are many nouns with classifiers in Chinese where attention shall be paid to choose different nouns to match different numerals", some students could figure out classifier if they saw an unknown word between a numeral and a noun in while reading. In this situation, they don't need to feel embarrassed or look up dictionary. Therefore, this kind of teaching grammar can be useful to improve student's reading ability

4. Emphasize on reading. We always say that grammar is fixed but language is creative. So, language cannot be well learnt by only reading grammatical books. For this point, many linguistic masters and experts of teaching Chinese as a second language have expressed deep thought. Shu-Xiang Lv (1962) once said, "It is better to read more articles than to read grammar books", and "Chinese knowledge shall be obtained by reading at anytime and anywhere". Unfortunately, the TCSL materials that most of us are using today, The Great Wall Chinese, contain very little reading requirement. Indeed, the knowledge points of each passage are enough and the textbook compilation is very practical, but extra essays are in shortage. Everybody knows that reading is an effective way for a student to accumulate vocabulary, practice language intuition and get familiar with Chinese. If students cannot learn Chinese in the language environment of Chinese, they will not be able to experience the charm of Chinese. If reading is neglected, then how the creative language originates? It is very hard for students to make great progress by remembering the grammatical points taught in the class and practicing several limited sentences. Here, I also suggest a passage with a certain reading scale shall be added behind the dialogues and practice of each unit in The Great Wall Chinese.

\section{CONCLUSIONS}

I didn't teach in Hungary for long; besides, most of the students I taught there started from zero. Therefore, all the strategies about Chinese grammars involved in this paper are made for foreign students who want to learn elementary Chinese. The grammatical phenomena in middle and senior Chinese teaching for foreigners are more complex and hard to explain. However, in my mind, conforming to the following principles can help obtain better effect in Chinese teaching for foreign students:

(1) Teaching grammars cannot be completed abandoned in teaching activities.

(2) Teaching grammars are different from study of Chinese grammars. In the classroom, control the teaching of grammar within a certain extent and do not talk too much about it. Use the most concise language and select grammars with the highest applicability and generalization degree to teach students from their perspective. The reason for why students learn Chinese is that they want to use it instead of explaining phenomenon. Sometimes, when a grammatical phenomenon occurs, we can clearly explain it while students do not dare to use it after class although they can understand it in the class. This kind of teaching grammars is also failure.

(3) During the process of practical teaching grammars, it's better to summarize grammatical features without a sign. Try to avoid the use of terminologies. For example, students have learnt English and known basic terms such as "noun", "verb", "adjective" and "subject". However, "complement" is a new word for Hungarian students. Teachers can tell students that a verb can be followed by a verb (phrase) or adjective (phrase) to express a movement result or an action in Chinese. When students know the necessary explanation, it will be easier for them to use the word. As another example, while teaching sentences of "ba", it is better to study in relaxing classroom labor instead of listing the grammatical features of sentences of "ba". We can simulate the scene of "class sweep up" and set "Let's Clean up Today" as our theme. Ask students to practice "Ni ba zhuo zi ca yi xia" (You go to clean the table), "Wo ba di sao yi xia" (I go to clean the ground), "Wo ba bo li ca gan jing le" (I have wiped the windows", and "Ta ba shu bao zheng li hao" (She has arranged the schoolbag well". We can even ask the students to clean the classroom for real and make them practice while cleaning. During cleaning, students will not think these sentences are a kind of practice; instead, they will regard the sentences as necessary parts of social communication. Practice makes perfect. In continuous practice, students can further study the verb-complement structure.

(4) Pay attention to student's reading quantity. The author always wrote some short but practical articles and read them to the students. At first, student found it was hard to understand. However, after several times 
SSHE 2015

of reading, the effect became more and more obvious. During this process, the students accumulated some extracurricular vocabularies and made much less grammatical mistakes. Because the articles were complementary reading, the students could choose the words and sentences they liked to remember and use. There was no pressure in learning the articles. Therefore, reading is more important for students of higher grades.

\section{REFERENCES}

[1] Lv, S.X. 1962. Chinese Learn English. Beijing: Commercial Press.

[2] Lv, S.X. 1979. Issues on Chinese Grammatical Analyses. Beijing: Commercial Press.

[3] Zhu, D.X. 1989. Statement in the 10th Anniversary Forum of Language Teaching and Linguistic Studies. Language Teaching and Linguistic Studies, (3).
[4] Lv, B.S. 1990. Outline of Foreign Language Teaching Development. Beijing: Beijing Language and Culture University Press.

[5] Cui, Y.H. Consideration about the Grammar System of Teaching Chinese as a Second Language. Beijing: Beijing Language and Culture University Press.

[6] Zhao, J.M. 1994. Some matters of principle in teaching foreigners Chinese grammar. Language Teaching and Linguistic Studies, (2).

[7] Lv, W.H. 1999. Research on the Grammar System of Teaching Chinese as a Second Language. Beijing: Beijing Language and Culture University Press,

[8] Li, Q. 2003. The Position and Role of Grammar in Teaching Chinese as a Second Language and Relevant Issues. Exploration on the Grammar in Teaching Chinese as a Second Language--Collected Papers of the First International Seminar for Grammar in Teaching Chinese as a Second Language. China Social Sciences Publishing House. 